\title{
A discrepancy in precipitable water among reanalyses and the impact of forcing dataset on downscaling in the tropics
}

H. G. Takahashi ${ }^{1,2}$, M. Hara ${ }^{2}$, M. Fujita ${ }^{2}$, and T. Yoshikane ${ }^{2}$

${ }^{1}$ Graduate School of Urban Environmental Sciences, Tokyo Metropolitan University, Hachio-ji, Tokyo, Japan

${ }^{2}$ Research Institute for Global Change, Japan Agency for Marine-Earth Science and Technology, Yokohama, Kanagawa, Japan

Received: 22 August 2012 - Accepted: 28 August 2012 - Published: 12 September 2012 Correspondence to: H. G. Takahashi (hiroshi3@tmu.ac.jp)

Published by Copernicus Publications on behalf of the European Geosciences Union.

Discrepancy of PW and impact on downscaling

H. G. Takahashi et al.

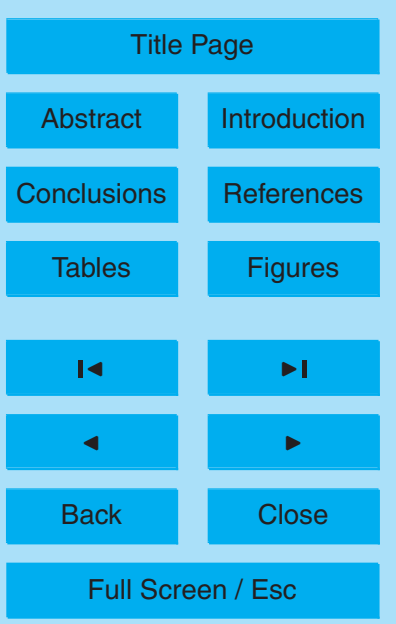

Printer-friendly Version

Interactive Discussion

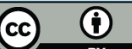




\section{Abstract}

Seven major reanalyses of precipitable water (PW) are compared in this paper. In addition, using a regional climate model, we also investigated the impact of the boundary conditions on downscaling simulations in the tropics with a particular focus on the dif-

5 ferences in the absolute value of PW among reanalyses.

Results showed that the absolute amounts of PW in some reanalyses were very small compared to the observation, although most spatial patterns of PW in the reanalyses agreed closely with the observation. Particularly over the tropics, most of reanalyses tended to have dry biases throughout the annual cycle. The range of interreanalysis dispersion in the tropical mean PW is very large compared with their seasonal variations of the tropical mean PW. In addition, the discrepancies of the 12-yr mean PW in July over the Southeast Asian monsoon region among the reanalyses exceeded their inter-annual standard deviation of the PW. Therefore, the inter-reanalyses dispersion in the tropical PW is significantly large.

15 We also conducted the downscaling experiments, which were forced by the different four reanalyses. The spatial and temporal variations of atmospheric circulation, including monsoon westerlies and various disturbances, were very similar among the reanalyses. However, the simulated precipitation was $40 \%$ less than the observed precipitation amounts, although the dry bias in the boundary conditions was only $6 \%$, and the simulated atmospheric circulation was also basically the same. This result indicates that the dry bias has large effects on precipitation in downscaling experiments over the tropics even if atmospheric circulation is well simulated. Downscaled models can provide realistic simulations of regional tropical climates only if the boundary conditions include realistic absolute amounts of PW. Use of boundary conditions that include realistic absolute amounts of $\mathrm{PW}$ in downscaling in the tropics is imperative at the present time.

\section{Discrepancy of PW and impact on downscaling}

H. G. Takahashi et al.

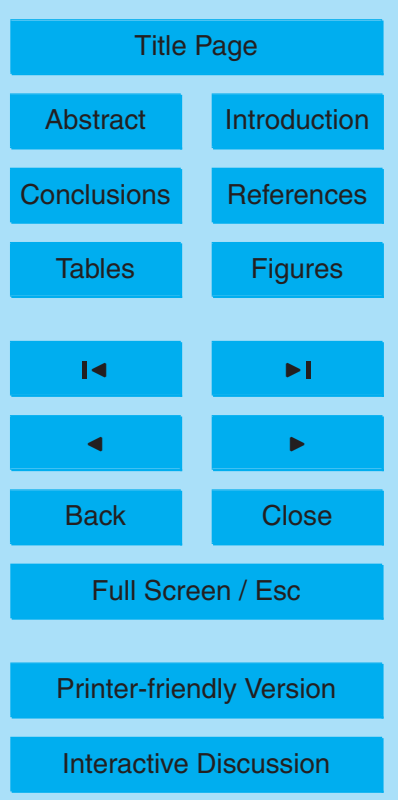




\section{Introduction}

Water vapor plays a major role in climate as a dominant feedback variable associated with radiative processes and moist dynamics. Particularly over the tropics, cloudprecipitation systems are very sensitive to spatial and temporal variations of water

5 vapor because moist convections are primarily dominant there, whereas, in the midlatitudes, weather systems, such as baroclinic waves, are dynamically controlled. To simulate the present climate and to project future climates in the tropics, atmosphereocean global climate models (AOGCMs) need to precisely simulate the amount of water vapor and its spatial-temporal variation because water vapor plays a major role in 10 the radiation budgets and latent heating of cloud-precipitation systems. Realistic simulation of the present global climate forced by latent heating in the tropics is otherwise very difficult. In addition, precise simulation of present regional climates and projection of future regional climates in the tropics by dynamical downscaling require precise boundary conditions of both atmospheric circulation and water vapor fields in the trop15 ics.

Trenberth et al. (2005) noted a large discrepancy in precipitable water (PW) between the National Centers for Environmental Prediction/National Center for Atmospheric Research (NCEP/NCAR) and the 40-yr Reanalysis (ERA40) of the European Centre for Medium-range Weather Forecasts (ECMWF), in spite of the fact that both are two major atmospheric circulation datasets. Water vapor fields in some reanalyses have been assimilated with microwave imager observations over the ocean, whereas water vapor fields in some other reanalyses have not. This difference can partly explain the discrepancy in PW. Most reanalyses show some systematic bias in the estimation of water and energy cycles (Trenberth et al., 2011). There is, thus, a requirement for a description of the differences in the water vapor fields.

It is noteworthy that reanalysis datasets are commonly used for evaluation of the performance of AOGCMs because the reanalysis datasets are very likely to be the best estimates of atmospheric circulation and water vapor fields. If AOGCMs are evaluated

\section{Discrepancy of PW and impact on downscaling}

H. G. Takahashi et al.

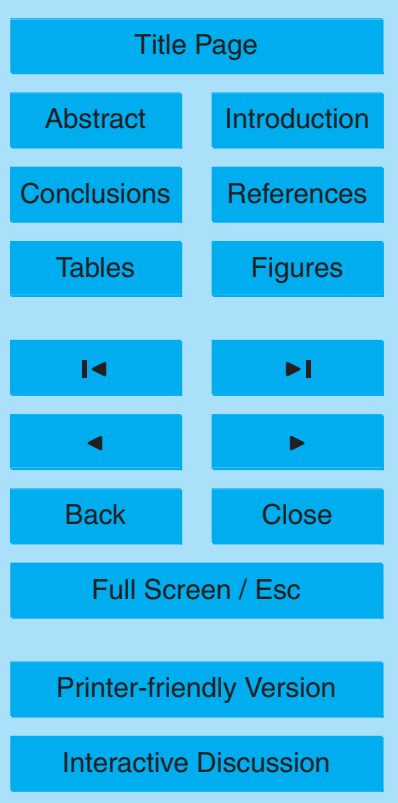


with different reanalysis datasets, the assessment of their performance will likely differ. Because reanalyses are assimilated with observations from some of the same sources, the differences in atmospheric circulation among reanalyses are probably smaller than those among AOGCMs.

5 Moreover, it is quite possible that the PW discrepancies between the reanalyses affect the regional climate in the tropics simulated by downscaling. Although the best reanalyses can be used for simulations of current regional climates, multi-AOGCMs should be used for future regional climate projections. This is because AOGCM projections of future climate include uncertainty, and the range of uncertainty should be 10 evaluated. Roads et al. (2003) showed that there were systematic seasonal precipitation errors in regional model simulations driven by the NCEP/NCAR reanalysis, and the errors were similar to the systematic error in the NCEP/NCAR reanalysis. They used a multi-model ensemble method and concluded that the downscaling results depended strongly on the forcing data. In addition, the downscaled climate changes remained uncertain over regions where the AOGCM projections disagreed (Christensen et al., 2007). To better understand how the use of boundary conditions from multi-AOGCM datasets for downscaling experiments over the tropics, we used reanalyses to investigate the impact of forcing dataset on downscaling simulations.

The primary purpose of this study was to objectively quantify the differences in the amounts of PW in the tropics among multiple reanalyses. We also investigate how the PWs in reanalyses are distributed adjacent to an observation to demonstrate the presence of biases in reanalyses. This study also investigates the impacts of different reanalysis datasets on regional climate simulations, which would be good practice for how we use multi-AOGCM datasets for downscaling in the tropics.

25 The remainder of this paper is arranged as follows. Section 2 documents the data used in this study and design of the numerical experiments. In Sect. 3, we investigate the PW discrepancies between reanalyses and the effects of downscaling on simulated precipitation in the tropics. Issues on PW in reanalyses and regional climate projections are discussed in Sect. 4, and conclusions are given in Sect. 5.

\section{Discrepancy of PW and impact on downscaling}

H. G. Takahashi et al.

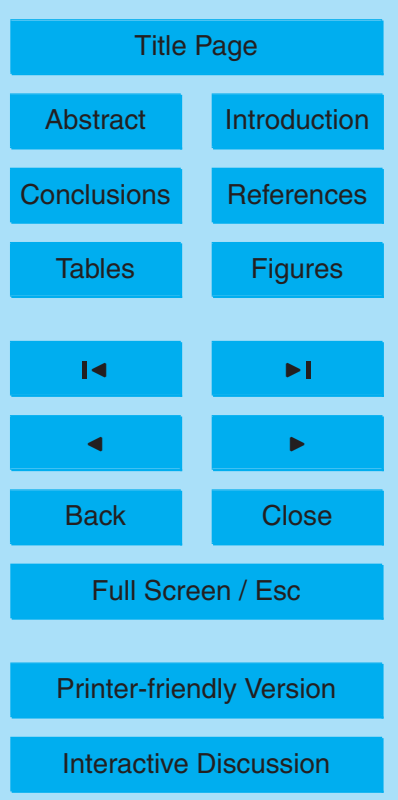

Interactive Discussion 


\section{Data and numerical experiment}

To quantify the inter-reanalysis discrepancy of PW, seven major reanalyses were used. Four are conventional: the ERA40 reanalysis (ERA40; Uppala et al., 2005), NCEP/Department of Energy reanalysis (DOE; NCEP2; Kanamitsu et al., 2002), $5 \mathrm{NCEP} / \mathrm{NCAR}$ reanalysis (NCEP1; Kalnay et al., 1996) and Japanese 25-yr reanalysis (JRA25; Onogi et al., 2007). The others, the ERA-interim reanalysis (ERAint; Berrisford et al., 2009), the NCEP climate forecast system reanalysis (CFSR; Saha et al., 2010) and NASA (National Aeronautics and Space Administration)'s Modern-Era Retrospective Analysis for Research and Applications (MERRA; Rienecker et al., 2011), are modern ones. In general we used one or several reanalyses as observations for the evaluation of present climate simulations by the AOGCMs.

To compare observed amounts of column-integrated water vapor with the reanalyses, we used NASA Water Vapor Project estimates (NVAP; Randel et al., 1996), which are based on satellite and conventional observations. Because NVAP was produced 15 mainly from radiosonde over land and from microwave imager over ocean, biases of NVAP can be similar to their biases. Over land, the PW observed by radiosonde was drier than that derived from ground-based global positioning system (GPS) measurements (Wang and Zhang, 2008). PW of NVAP was drier than that observed by TOPEX/POSEIDON microwave radiometer over ocean (Simpson et al., 2001). Thus, NVAP may have a slight dry bias. NVAP and the four reanalyses were available from January 1988 to December 1999.

Downscaling from reanalyses or AOGCMs is necessary for the simulation and projection of current and future regional climates, which cannot be resolved by reanalyses or AOGCMs. To understand the effect of different boundary conditions on downscaling simulations, we conducted downscaling experiments using a non-hydrostatic regional climate model, the Advanced Weather Research and Forecasting (WRF) modeling system (Skamarock et al., 2008) ver. 3.3. We used four different reanalyses, ERAint, ERA40, NCEP2, and NCEP1, as initial and lateral boundary conditions, to understand

\section{Discrepancy of PW and impact on downscaling}

H. G. Takahashi et al.

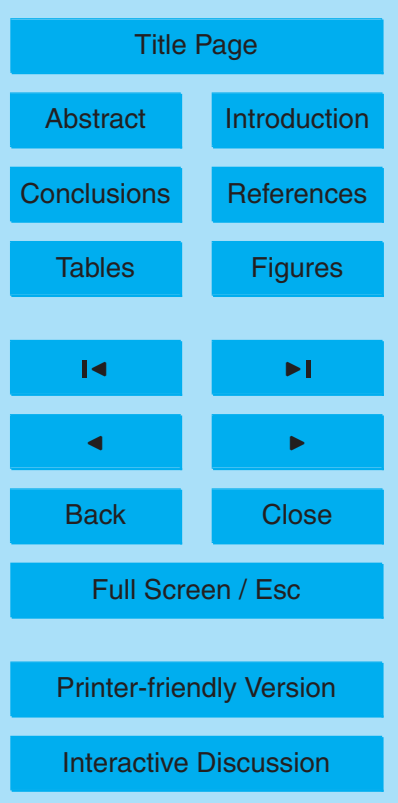


the effect of downscaling from different boundary conditions. The reason that we chose the four reanalyses is presented in Sect. 3.1. In short, we chose the four reanalyses in terms of the absolute values of water vapor over the tropics. ERAint is the closest to the observation, ERA40 has a wet bias, NCEP2 has a somewhat dry bias, and 5 NCEP1 is the driest. Thus, downscaling experiments forced by the four reanalyses can be used to investigate the impact of water vapor amount of the boudanry conditions, because we show that the $850-\mathrm{hPa}$ wind patterns of the reanalyses are basically the same (Sect. 3.3). The spatial resolutions of ERAint, ERA40, NCEP2, and NCEP1 in the downscaling experiments are $1.5^{\circ}, 2.5^{\circ}, 2.5^{\circ}$ and $2.5^{\circ}$, respectively. We named the 10 experiments DS-ERAint, DS-ERA40, DS-NCEP2, and DS-NCEP1, respectively. As the computational target region, we selected the Southeast Asian monsoon region, which is an area with one of the highest rainfalls worldwide. We selected July 1998 as the simulation period. The simulation period of the downscaling experiments was from 29 June 1998 to 1 August 1998. The first two days of the simulations were not used as a spin-up 15 period. We also conducted downscaling experiments driven by the four reanalyses for June 1998, and the results were similar to the downscaling experiments for July 1998. The model domains are shown in Fig. 1. The horizontal grid increment of the coarse domain was $17.5 \mathrm{~km}(137 \times 121$ grids in the east-west and north-south directions), and that of the two-way nested domain was $3.5 \mathrm{~km}(391 \times 311$ grids in the east-west and north-south directions). Both domains had 27 terrain-following vertical levels. Because experiments with cumulus convective parameterization (CCP) gave a very unrealistic pattern and the total amount of rainfall (Takahashi et al., 2009, 2010b), we did not apply CCP in either domain. The WRF single-moment six-class microphysics scheme (Hong and Lim, 2006), the Mellor-Yamada Nakanishi and Niino Level 2.5 planetary boundary 25 layer scheme (Nakanishi and Niino, 2004), and the Noah land-surface model (Chen and Dudhia, 2001) were also used.

To evaluate the simulated precipitation in July 1998, we used the Global Satellite Mapping of Precipitation (GSMaP) microwave radiometer (MWR) dataset (Kubota et al., 2007) generated from passive microwave radiometer data. The dataset has

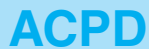

12, 23759-23791, 2012

\section{Discrepancy of PW and impact on downscaling}

H. G. Takahashi et al.

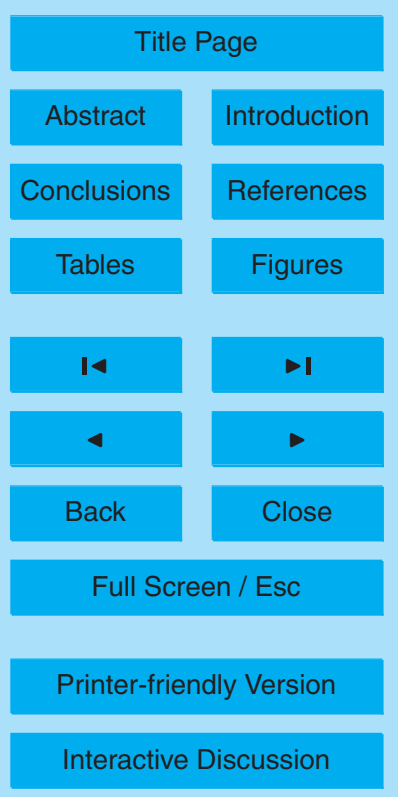


global coverage between $60^{\circ} \mathrm{S}$ and $60^{\circ} \mathrm{N}$, with a $0.25^{\circ}$ spatial resolution and 1-h temporal resolution. The coverage spans $9 \mathrm{yr}$ from 1998 to 2006 . We used monthly averaged values.

\section{Results}

\subsection{Discrepancy of precipitable water in reanalyses}

This subsection is an investigation of the discrepancies in PW among the eight reanalyses. We compare annual global mean PWs and annual tropical mean PWs over $30 \mathrm{yr}$ from 1979 to 2008 except for ERA40 and NVAP (Fig. 2). PW of ERA40 was averaged over $23 \mathrm{yr}$ from 1979 to 2001, and PW of NVAP was averaged over $12 \mathrm{yr}$ from 1988 10 to 1999 . The area of the tropics is defined within $25^{\circ} \mathrm{S}-25^{\circ} \mathrm{N}$. The global and tropical mean PWs of ERAint and JRA25 were close to the observation. A few new generation reanalyses, such as MERRA and CFSR, have somewhat dry biases in both global and tropical averages. PW of NCEP2 was drier over the tropics. PW of ERA40 was wettest for the global and tropical means. NCEP1 has the driest bias in global and tropical 15 averages. Because the atmospheric circulations over Southeast Asia are basically the same among reanalyses, as we show in the following subsection, we can choose the four reanalyses for the inter-comparison of PWs and the downscaling experiments. ERAint is the closest to the observation, and ERA40 has a strong wet bias in the tropics. In addition, NCEP1 has a strong dry bias, and NCEP2 has a somewhat dry bias in the tropics. Downscaling experiments from the four reanalyses can be used to investigate the impacts of forcing dataset in terms of sensitivity to the absolute amount of water vapor.

The seasonal differences in tropical mean and global mean PW among reanalyses and observation are shown in Fig. 3. The tropical mean seasonal cycles of the reanaly-

PW of NCEP1 in May was comparable with or smaller than the minimum values of PW

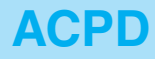

12, 23759-23791, 2012

\section{Discrepancy of PW and impact on downscaling}

H. G. Takahashi et al.

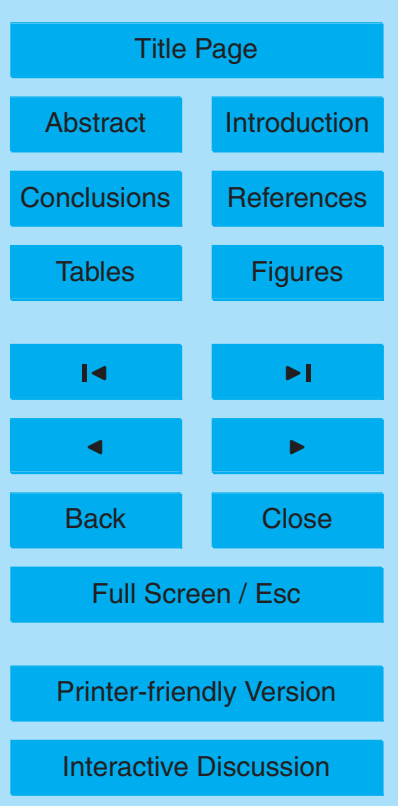


in most of the reanalyses, which indicated that the dry bias in NCEP1 was very large. On the other hand, the seasonal march of PW of ERA40 showed wet biases throughout the annual cycle, while the seasonal march of the other reanalyses indicated dry biases throughout the annual cycle. Global mean seasonal marches also showed similar sea5 sonal variations of PW among the reanalyses and observation (Fig. 3b). However, the absolute amounts of PW deviated among the reanalyses and observation throughout the annual cycle. These results indicate that the sign of bias in PW in each reanalysis was unchanged throughout the season.

Compared with the range of inter-reanalysis dispersion in the global mean $\mathrm{PW}$, the 10 range of inter-reanalysis dispersion in the tropical mean PW is very large. The range of inter-reanalysis dispersion in the tropical mean PW is from about $1.5 \mathrm{~mm}$ to $3 \mathrm{~mm}$, as estimated from the difference between PW of ERA40 and NCEP1. The range of interreanalysis differences in the tropical mean $\mathrm{PW}$ is comparable or larger than a range of seasonal differences in tropical PW, which were about $2 \mathrm{~mm}$ at a maximum. This result indicated that PWs in the tropics have large biases throughout the annual cycle in most of the reanalyses. It must also be noted that most of reanalyses, including new generation reanalyses, have a dry tendency, particularly over the tropics. Somewhat dry biases were found even in new generation reanalyses, which indicated that the problems of dry biases in reanalyses still existed but were gradually being corrected in new-generation reanalyses.

\subsection{Spatial distribution of precipitable water in the tropics}

Figure 4 shows the climatological precipitable water (PW) in reanalyses over the Asian monsoon region during a typical rainy month (July). The climatology is the 12-yr mean from 1988 to 1999. The highest PW of NVAP occurred over the Bay of Bengal, which 25 is one of the highest rainfall regions in the world. A high PW of NVAP was also observed over the South China Sea and the Western North Pacific. Maxima in PW were also found over the Bay of Bengal, South China Sea, and Western North Pacific in ERAint, ERA40, NCEP2 and NCEP1. These results are in close agreement with the

\section{Discrepancy of PW and impact on downscaling}

H. G. Takahashi et al.

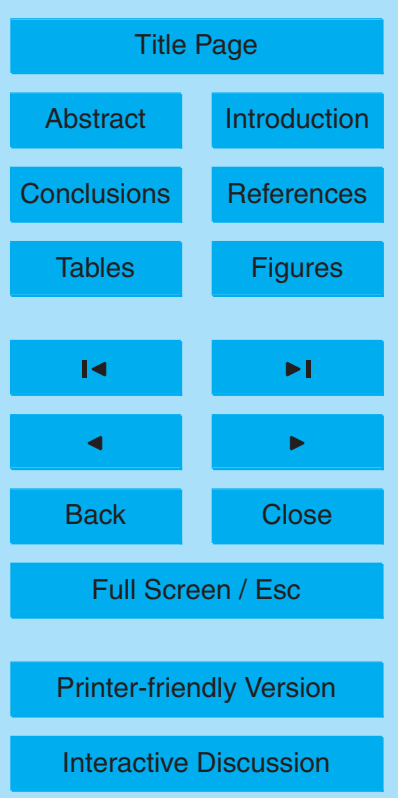


PW observations. On the other hand, the absolute amounts of PW of NCEP2 and NCEP1 were markedly lower than the observed PW over Southeast Asia, whereas those of PW of ERAint and PW of ERA40 were slightly higher. Although the results of all four reanalyses confirmed the spatial pattern in PW in July, the absolute amounts of 5 PW were clearly too small in some reanalyses. The spatial resolution of original model of reanalysis can affect the spatial distribution in $\mathrm{PW}$ on regional scale, such as west of the Indian subcontinent, over the coast of Bay of Bengal, and over Northern India. However, the effects of different spatial resolutions of the models on the reproductivity of spatial distribution in PW on large scale were not clear.

10 Examination of the climatological PW in the tropics (Fig. 5) provides some understanding of the differences in the PWs for the northern summer and winter over the tropics. PW of ERAint was in good agreement with PW of NVAP in the northern summer and winter. Conversely, a dry bias was found in PW of NCEP1 over all of the tropics in both the northern summer and winter. PW of NCEP2 was similar to PW of 15 NCEP1, although the bias was smaller. As shown in Figs. 2 and 3, the same tendency in the other months was evident in each reanalysis, which implies that the water vapor amount depended on the reanalysis. It must be noted that the spatial patterns were quite similar in all four reanalyses. In addition, the mean atmospheric circulation fields in the lower troposphere were quite similar in the four reanalyses (see Sect. 3.3). Nevertheless, discrepancies in the absolute amounts of PW in the major reanalyses were evident globally, particularly over the tropics. The fact that these discrepancies in PW were apparent for the entire tropics and throughout the annual cycle indicates that this problem is not a regional but a global issue.

To quantify the PW dispersion among the reanalyses, we investigated the clima25 tological mean PW in July over a period of $12 \mathrm{yr}$ from 1988 to 1999 and the interannual standard deviation in PW in July over a period of $30 \mathrm{yr}$ from 1979 to 2008 (over $23 \mathrm{yr}$ for ERA40) (Fig. 6). The Bay of Bengal is one of the highest PW regions, and $\mathrm{PW}$ over the region can substantially affect the water vapor transport to the Southeast Asian monsoon regions, which we determined as the target region for our downscaling

\section{Discrepancy of PW and impact on downscaling}

H. G. Takahashi et al.

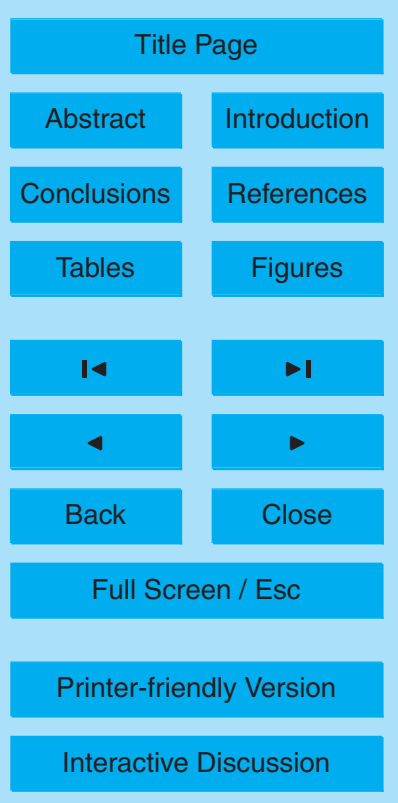


experiments. For these reasons, we examined the PWs over the Bay of Bengal. The monthly mean observed PW over the Bay of Bengal in July is about $60 \mathrm{~mm}$. PW of ERAint slightly overestimated, PW of ERA40 somewhat overestimated, and PW of NCEP1 markedly underestimated that observation. The dry bias was more than $10 \%$ 5 by the NCEP 1 and $5 \%$ by the NCEP2. The inter-annual standard deviation of the PWs was about $3 \%$ of the mean absolute value of the PWs in all four reanalyses. The fact that the dispersion in PW between NCEP1 and ERAint and that between PW of NCEP2 and PW of ERAint were much larger than $3 \%$ indicates that the discrepancy of PWs among reanalyses was objectively large. Because a $30-y r$ climate change is generally 10 much smaller than its interannual variation, long-term changes in PW might be negligibly small. Regarding the absolute amount of PW over the tropics, it is noteworthy that the discrepancies among the major reanalyses were quite large. Because we investigated the impact of forcing dataset on downscaling simulations in July 1998, we also checked the amount of PW in July 1998, which showed that the amount of PW was

\subsection{Impact of forcing dataset on the downscaling simulations}

We investigated the impact of forcing boundary conditions on dynamical downscaling simulations in terms of the differences in PWs over the Asian monsoon region. Over this region, water vapor transport is very important. Large amounts of precipitation result 20 not only from local evaporation from the surface but also from transport of water vapor into the region by the monsoon westerlies. The spatial distributions of the amount of simulated rainfall forced by the four reanalyses are shown in Fig. 7 for the month of July 1998.

The monthly rainfall distribution of DS-ERAint and DS-ERA40 (Fig. 7b, c) over and 25 around the Indochina Peninsula was well simulated compared to the observed distribution based on the GSMaP (Fig. 7a) and Tropical Rainfall Measuring MissionPrecipitation Radar (TRMM-PR) climatology data (Takahashi et al., 2010a). However, the monthly simulated rainfall driven by the NCEP1 (Fig. 7e) was too low over the

\section{Discrepancy of PW and impact on downscaling}

H. G. Takahashi et al.

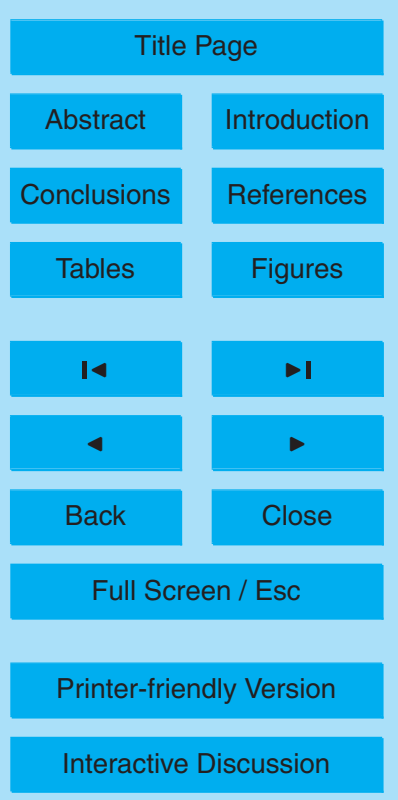


entire domain. The amount of rainfall simulated by the DS-NCEP2 (Fig. 7d) was lower over the Eastern Bay of Bengal, although the rainfall simulated by the DS-NCEP2 was higher than the rainfall simulated by the DS-NCEP1. The amounts of simulated rainfall averaged over and around the Indochina Peninsula are shown in Fig. 8. The simulated 5 rainfall in DS-NCEP2 and DS-NCEP1 was half or less of that forced by ERA40 and ERAint and the GSMaP observations, although the dry bias of NCEP2 and NCEP1 as boundary conditions was only $6 \%$ and $13 \%$, respectively.

To understand the differences in the simulated precipitation amount among the downscaling experiments, longitude-time cross sections of the simulated precipitation and 10 time series of domain-averaged precipitable water are shown in Fig. 9. In the DSERAint, active precipitation systems between $100^{\circ} \mathrm{E}$ and $104^{\circ} \mathrm{E}$ were found around 1 July to 10 July, 13 July to 15 July, and 28 July to 31 July. At the same time, precipitation over the Bay of Bengal (west of $98^{\circ} \mathrm{E}$ ) and Eastern Indochina Peninsula (east of $106^{\circ} \mathrm{E}$ ) was also active (Fig. 9a). The precipitation systems showed distinct diurnal cy15 cles, which have been observed by TRMM-PR (Takahashi et al., 2010a) and simulated by a regional climate model (Takahashi et al., 2010b). DS-ERA40 showed similar precipitation systems during almost the same time (Fig. 9b). However, the longitude-time cross sections of DS-NCEP1 showed that active precipitation systems were found only from 27 July to 31 July (Fig. 9c). In addition, precipitation over the Bay of Bengal and 20 Eastern Indochina Peninsula was also weaker. It is noteworthy that active precipitation systems can be found when domain-averaged PW exceeds approximately $54 \mathrm{~mm}$ in all of the downscaling experiments. This suggests that precipitation systems become active when PW exceeds a threshold value. Therefore, the absolute amount of PW is very likely to be the primary factor to determine the activation of precipitation system.

25 We also examined differences in atmospheric circulations on the boundary conditions, which can affect the differences in the simulated precipitation. Spatial pattern correlation of $850-\mathrm{hPa}$ zonal and meridional winds over the Southeast Asian monsoon region showed statistically significant and high values, which suggests that differences in atmospheric circulation patterns among the boundary conditions were negligibly

\section{Discrepancy of PW and impact on downscaling}

H. G. Takahashi et al.

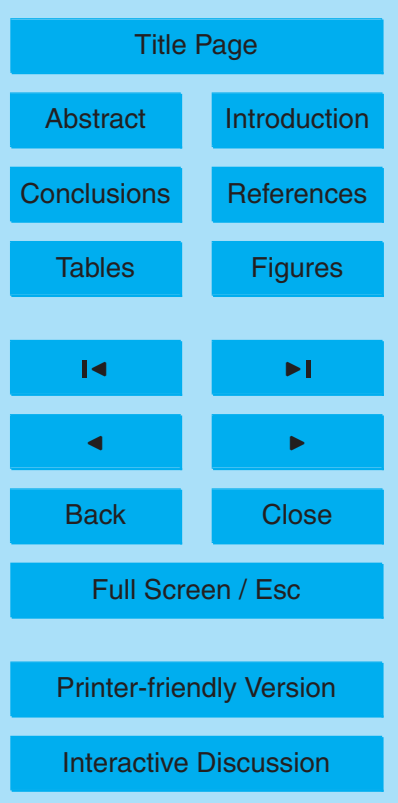


small (Table 1). Moreover, the strength of the monsoon westerly was essentially the same among the reanalyses (Table 1), and we confirmed that the atmospheric circulation patterns, such as the low-level monsoon westerlies and upper-level easterlies associated with the Tibetan High, were basically the same for the four reanalyses (not 5 shown). To understand the differences of temporal variation in atmospheric circulation among the boundary conditions, Table 2 shows that the correlation coefficients among the forced daily zonal and meridional winds of boundary conditions over the Southeast Asian monsoon region were very high. These results indicate that the spatial and temporal variations in the forced dynamical conditions were basically the same.

10 Furthermore, we examined the possibility that mass convergence can compensate the deficiency of water vapor over the domain. Table 3 shows the $850-\mathrm{hPa}$ wind convergence over the Southeast Asian monsoon region among the boundary conditions, which indicates that mass convergence was not correlated with the simulated precipitation amounts. For example, the strongest convergence over the Southeast Asian domain was found in ERA40, while the weakest convergence was found in ERAint. The wind convergences over the Southeast Asian domain in NCEP1 and NCEP2 were weaker than those in ERA40 but sufficiently stronger than those in ERAint. This result suggests that wind convergence was not the primary factor determining precipitation over the region. Of course, large-scale wind convergence may compensate for a shortcant factor for precipitation, we calculated the wind divergence at $850 \mathrm{hPa}$ to divide the effects of water vapor convergence into water vapor fields and wind fields.

In addition, we examined spatial and temporal variations of the simulated atmospheric circulations. The spatial patterns in the simulated $850-\mathrm{hPa}$ winds among 25 the downscaling experiments were very similar, which were statistically significant at a $99 \%$ confidence limit (Table 4). Table 5 shows the temporal variations of the simulated $850-\mathrm{hPa}$ zonal and meridional winds are highly correlated among the downscaling experiments, which were statistically significant at a $99 \%$ confidence limit. Thus, the

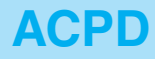

12, 23759-23791, 2012

\section{Discrepancy of PW and impact on downscaling}

H. G. Takahashi et al.

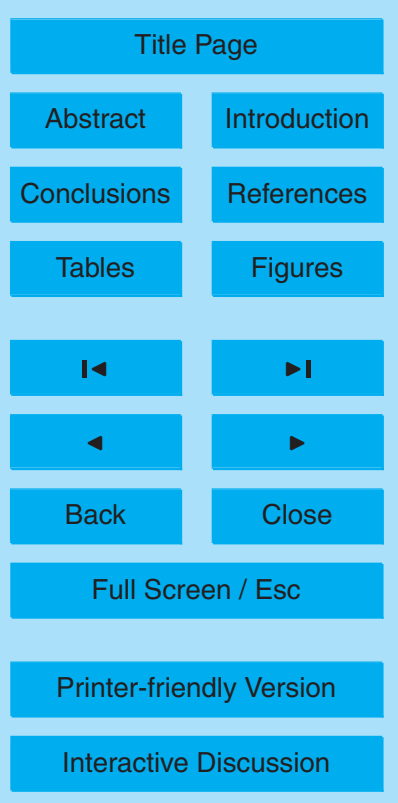


simulated temporal variations of atmospheric circulation were also very similar, including synoptic and intraseasonal disturbances, in all of the downscaling experiments.

Although the forced and simulated spatial and temporal variations of atmospheric circulation were very similar among the downscaling experiments, the simulated rainfall 5 distributions differed markedly among the downscaling experiments. Therefore, these results suggest that, in downscaling experiments, rainfall over the tropics is very sensitive to water vapor amounts in the boundary conditions. It is also noteworthy that a dry bias has large effects on precipitation in downscaling experiments over the tropics, while the effects of a wet bias in the boundary conditions in downscaling exper10 iments are relatively small because the difference of simulated precipitation between DS-ERA40 and DS-ERAint was relatively small. In addition, when models run without a realistic PW but with realistic atmospheric circulation, the realistic simulation of precipitation in the tropics is quite difficult to obtain.

\section{Discussion}

15 The results presented in the previous section have shown that most of the reanalysis datasets, including new generation reanalyses, have dry biases, particularly over the tropics. In addition, the discrepancies in PWs were very large even among major reanalyses that have commonly been used as observational datasets for the evaluation of AOGCMs. The differences in PWs between the reanalyses may be smaller than those among AOGCMs because the reanalyses were assimilated to some extent with the same observational sources. Moreover, the performance of the simulation of the present climate with each AOGCM has been evaluated on the basis of a comparison with one of the major reanalyses. Thus, it is quite possible that AOGCMs have a similar dry bias and larger inter-AOGCM discrepancy compared with the reanalyses.

Only a $6 \%$ discrepancy in PW caused a much larger discrepancy of simulated rainfall in the downscaling experiments over a tropical region, although the forcing atmospheric circulations were basically the same. The fact that Roads et al. (2003) found a similar

\section{Discrepancy of PW and impact on downscaling}

H. G. Takahashi et al.

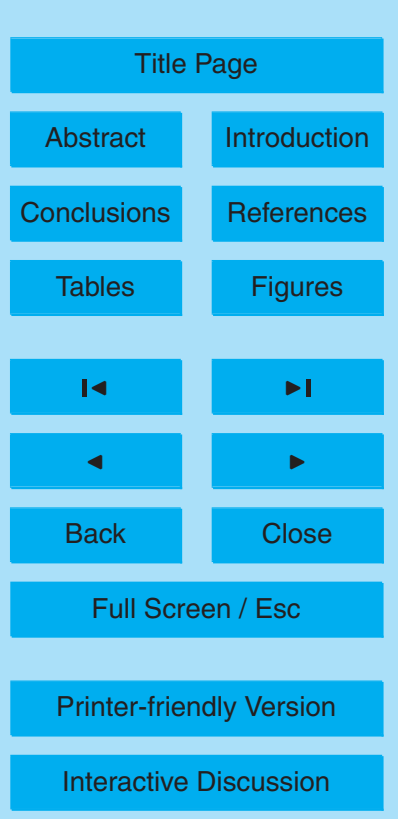


dry bias in boundary conditions and in downscaled regional climates in downscaling experiments with multi-regional climate models over the region of the American tropics probably indicates that the multi-regional climate model ensemble method cannot cancel out the significant effect of dry bias in boundary conditions in the tropics. It is 5 noteworthy that, although simulated precipitation was not very sensitive to a wet bias, it was very sensitive to a dry bias in the tropics. This result suggests that the sensitivity of precipitation to PW is highly non-linear. Even if several boundary conditions associated with PW are isotropically distributed in a downscaling experiment over the tropics, the downscaled regional climates are unlikely to be isotropically distributed. There10 fore, a downscaled regional climate over the tropics derived from an ensemble-mean multi-AOGCM is likely to be quite different from an ensemble mean downscaled from regional climate averaged over several climates downscaled from boundary conditions of the ensemble members.

Hence, our results suggest that both the variable components and the absolute 15 amounts of PW in reanalyses and AOGCMs must be close to observations in order to accurately simulate and project regional climate changes, particularly over the tropics. Because a downscaling model can simulate realistic regional climates in the tropics only with realistic fields of the absolute amount of water vapor, only reanalyses or AOGCMs that can show or simulate realistic absolute amounts of water vapor should be used in downscaling experiments in the tropics for the time being. In addition, correction for the bias of individual variables in the boundary conditions may have adverse effects because each physical variable in the boundary conditions is determined from energy balance in each model. Furthermore, the energy budget at the surface is basically coupled with the hydrological cycle on the Earth (Wild and Liepert, 2010), although the cause and magnitude of variation of the hydrological cycle responsible for global climate change have yet to be fully understood. The problem of dry or wet biases should be corrected because the biases of water vapor in the reanalyses or AOGCMs may affect the reproducibility of a tropical and global climate. The correction for the bias of individual variables is inconsistent with the energy and water budgets in each model.

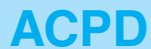

12, 23759-23791, 2012

\section{Discrepancy of PW and impact on downscaling}

H. G. Takahashi et al.

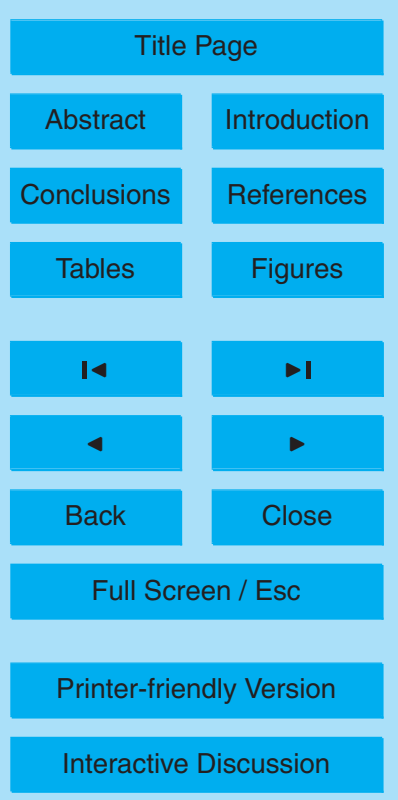




\section{Conclusions}

We compared the PWs over the tropics among the seven major reanalyses: ERAint, CFSR, MERRA, JRA25, ERA40, NCEP2, and NCEP1. We also conducted downscaling experiments over the Southeast Asian monsoon region forced by the four different 5 reanalyses to understand the impact of forcing dataset on downscaling simulations with a focus on water vapor fields using a non-hydrostatic regional climate model.

Most of the tropical mean PW in each reanalysis was lower than the observation throughout the annual cycle. The tropical mean and global mean PWs were not isotropically distributed adjacent to the observation. They have dry biases. The range of inter10 reanalysis dispersion in the tropical mean PW was much larger than their seasonal variations of the tropical mean $\mathrm{PW}$. In addition, the range of inter-reanalysis dispersion in the tropical mean PW was larger than the inter-annual standard deviations of the reanalyses. Therefore, the discrepancy of PW among the reanalyses was substantially large. Because the spatial patterns of PW in the reanalyses were in close agreement 15 with the observations, dry biases were found over the whole tropics. In particular, the dry bias in NCEP1 and NCEP2 over the Bay of Bengal was about $5 \%$ and $12 \%$, respectively, and the inter-annual standard deviations of PW were about $3 \%$. The mean atmospheric circulation patterns, such as the low-level monsoon westerlies and upperlevel easterlies and synoptic and intraseasonal disturbances, were nevertheless very similar among the reanalyses.

We also conducted downscaling experiments, which were forced by four different reanalyses selected in terms of the absolute values of PW over the tropics. The spatial and temporal variations of atmospheric circulation, including monsoon westerlies and various disturbances, were very similar among the reanalyses. However, simulated precipitations largely deviated in association with the absolute values in PW of the boundary conditions. ERAint, which had realistic PWs, forced simulated rainfall that was in good agreement with the observed rainfall. Contrariwise, the amounts of rainfall simulated by DS-NCEP1 and DS-NCEP2 were very small. It was noteworthy that the

\section{Discrepancy of PW and impact on downscaling}

H. G. Takahashi et al.

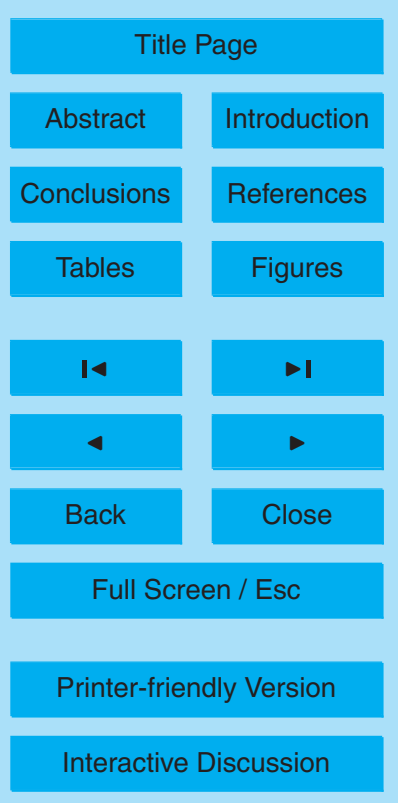


dry bias of only $6 \%$ in the forcing data resulted in a simulated precipitation of about $60 \%$ of the observed amount in the Southeast Asian monsoon region, whereas the effects of the wet bias were small. This result suggests that the impact of forcing dataset on the simulated precipitation as a function of PW in the boundary conditions are highly 5 non-linear. Therefore, accurate projections of future regional climates in the tropics will require realistic simulations not only of the spatial-temporal variations in water vapor but also of the absolute amounts of water vapor in AOGCMs because AOGCMs are the only tools that can project future global climate and downscaling from them is the only method to project regional climate. Because downscaling models can simulate re10 alistic regional climate in the tropics only with boundary conditions that include realistic fields of absolute amounts of water vapor, only reanalyses or AOGCMs that can show or simulate realistic absolute amounts of water vapor should be used in downscaling experiments in the tropics for the time being. Finally, assessment of discrepancies in reanalyses should continue because understanding this problem can facilitate the assessment of biases and, hence, the improvement of AOGCMs. Continuous comparison and improvement of reanalyses and AOGCMs are necessary.

Acknowledgements. The authors thank two anonymous reviewers for their helpful suggestions and comments. This work was partly supported by the Global Environment Research Fund (RFa-1101) of the Ministry of the Environment, Japan and by the "Green Network of Excellence (GRENE)" program of the Ministry of Education, Culture, Sports, Science, and Technology (MEXT), Japan.

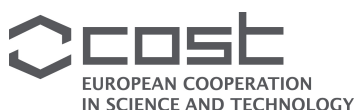

This publication is supported by COST - www.cost.eu

\section{ACPD}

12, 23759-23791, 2012

\section{Discrepancy of PW and impact on downscaling}

H. G. Takahashi et al.

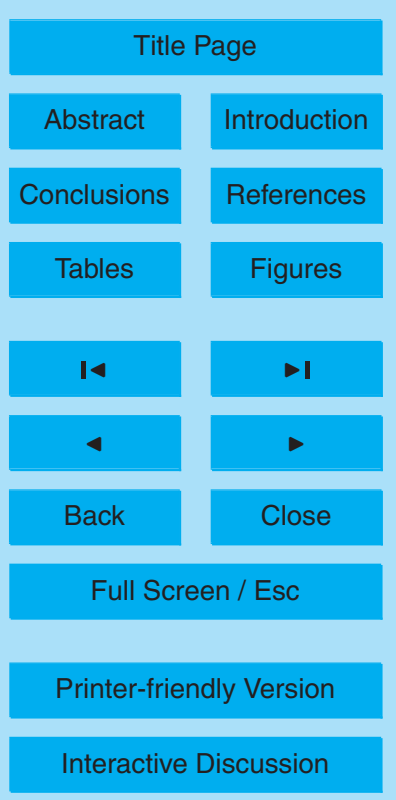




\section{References}

Berrisford, P., Dee, D., Fielding, K., Fuentes, M., Kallberg, P., Kobayashi, S., and Uppala, S.: The ERA-Interim Archive., ERA report series 1, European Centre for Medium-Range Weather Forecasts, 2009. 23763

5 Chen, F. and Dudhia, J.: Coupling an advanced land surface-hydrology model with the Penn State-NCAR MM5 modeling system. Part I: Model implementation and sensitivity, Mon. Weather Rev., 129, 569-585, 2001. 23764

Christensen, J., Hewitson, B., Busuioc, A., Chen, A., Gao, X., Held, R., Jones, R., Kolli, R., Kwon, W., Laprise, R., Magana Rueda, V., Mearns, L., Menendez, C. G., Räisänen, J., Rinke, A., Sarr, A., Whetton, P., Arritt, R., Benestad, R., Beniston, M., Bromwich, D., Caya, D., Comiso, J., de Elia, R., and Dethloff, K.: Regional climate projections, Climate Change, 2007: The Physical Science Basis, Contribution of Working group I to the Fourth Assessment Report of the Intergovernmental Panel on Climate Change, University Press, Cambridge, Chapter 11, 847-940, 2007. 23762

15 Hong, S. and Lim, J.: The WRF single-moment 6-class microphysics scheme (WSM6), J. Korean Meteor. Soc, 42, 129-151, 2006. 23764

Kalnay, E., Kanamitsu, M., Kistler, R., Collins, W., Deaven, D., Gandin, L., Iredell, M., Saha, S., White, G., Woollen, J., Zhu, Y., Leetmaa, A., Reynolds, B., Chelliah, M., Ebisuzaki, W., Higgins, W., Janowiak, J., Mo, K. C., Ropelewski, C., Wang, J., Jenne, R., and Joseph, D.: The NCEP/NCAR 40-year reanalysis project, B. Am. Meteorol. Soc., 77, 437-471, 1996. 23763

Kanamitsu, M., Ebisuzaki, W., Woollen, J., Yang, S., Hnilo, J., Fiorino, M., and Potter, G.: NCEPDOE AMIP-II reanalysis (R-2), B. Am. Meteorol. Soc., 83, 1631-1644, 2002. 23763

Kubota, T., Shige, S., Hashizume, H., Aonashi, K., Takahashi, N., Seto, S., Takayabu, Y., Ushio, $25 \quad$ T., Nakagawa, K., Iwanami, K., Kachi, M., and Okamoto, K.: Global precipitation map using satellite-borne microwave radiometers by the GSMaP project: production and validation, IEEE Geosci. Remote S., 45, 2259-2275, 2007. 23764

Nakanishi, M. and Niino, H.: An improved Mellor-Yamada level-3 model with condensation physics: its design and verification, Bound.-Lay. Meteorol., 112, 1-31, 2004. 23764

30 Onogi, K., Tsutsui, J., Koide, H., Sakamoto, M., Kobayashi, S., Hatsushika, H., Matsumoto, T., Yamazaki, N., Kamahori, H., Takahashi, K., Kadokura, S., Wada, K., Kato, K., Oyama, R.,

\section{Discrepancy of PW and impact on downscaling}

H. G. Takahashi et al.

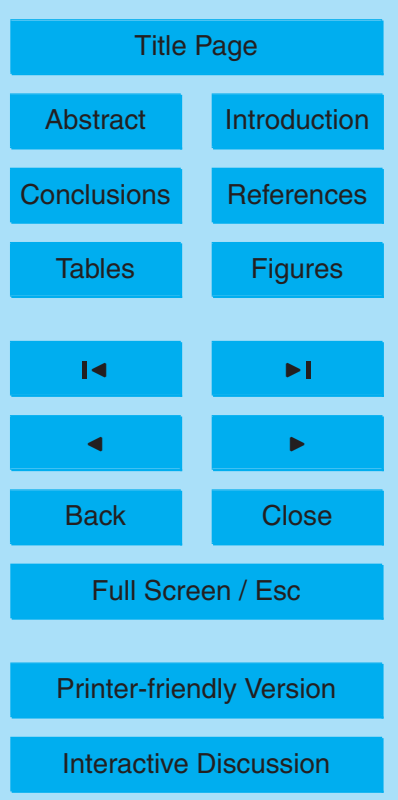


Ose, T., Mannoji, N., and Taira, R.: The JRA-25 reanalysis, J. Meteorol. Soc. Jpn., 85, 369432, 2007. 23763

Randel, D., Haar, V., Thomas, H., Stephens, G., Greenwald, T., Ringerud, M., and Combs, C.: A new global water vapor dataset, B. Am. Meteorol. Soc., 77, 1233-1246, 1996. 23763

5 Rienecker, M. M., Suarez, M. J., Gelaro, R., Todling, R., Bacmeister, J., Liu, E., Bosilovich, M. G., Schubert, S. D., Takacs, L., Kim, G.-K., Bloom, S., Chen, J., Collins, D., Conaty, A., da Silva, A., Gu, W., Joiner, J., Koster, R. D., Lucchesi, R., Molod, A., Owens, T., Pawson, S., Pegion, P., Redder, C. R., Reichle, R., Robertson, F. R., Ruddick, A. G., Sienkiewicz, M., and Woollen, J.: MERRA: NASA's modern-era retrospective analysis for research and 10 applications, J. Climate, 24, 3624-3648, 2011. 23763

Roads, J., Chen, S., Cocke, S., Druyan, L., Fulakeza, M., LaRow, T., Lonergan, P., Qian, J., and Zebiak, S.: International Research Institute/Applied Research Centers (IRI/ARCs) regional model intercomparison over South America, J. Geophys. Res., 108, 4425, doi:10.1029/2002JD003201, 2003. 23762, 23771

15 Saha, S., Moorthi, S., Pan, H.-L., Wu, X., Wang, J., Nadiga, S., Tripp, P., Kistler, R., Woollen, J., Behringer, D., Liu, H., Stokes, D., Grumbine, R., Gayno, G., Wang, J., Hou, Y.-T., Chuang, H.-Y., Juang, H.-M. H., Sela, J., Iredell, M., Treadon, R., Kleist, D., van Delst, P., Keyser, D., Derber, J., Ek, M., Meng, J., Wei, H., Yang, R., Lord, S., van den Dool, H., Kumar, A., Wang, W., Long, C., Chelliah, M., Xue, Y., Huang, B., Schemm, J.-K., Ebisuzaki, W., Lin, R., Xie, P., Chen, M., Zhou, S., Higgins, W., Zou, C.-Z., Liu, Q., Chen, Y., Han, Y., Cucurull, L., Reynolds, R. W., Rutledge, G., and Goldberg, M.: The NCEP climate forecast system reanalysis, B. Am. Meteorol. Soc., 91, 1015-1057, 2010. 23763

Simpson, J., Berg, J., Koblinsky, C., Hufford, G., and Beckley, B.: The NVAP global water vapor data set: independent cross-comparison and multiyear variability, Remote Sens. Environ., 76, 112-129, 2001. 23763

Skamarock, W. C., Klemp, J. B., Dudhia, J., Gill, D. O., Barker, D. M., Duda, M. G., Huang, X.Y., Wang, W., and Powers, J. G.: A description of the Advanced Research WRF version 3, NCAR Technical Note, NCAR/TN-475+STR, 2008. 23763

Takahashi, H. G., Yoshikane, T., Hara, M., and Yasunari, T.: High-resolution regional climate 30 simulations of the long-term decrease in September rainfall over Indochina, Atmos. Sci. Lett., 10, 14-18, 2009. 23764

Takahashi, H. G., Fujinami, H., Yasunari, T., and Matsumoto, J.: Diurnal rainfall pattern observed by tropical rainfall measuring mission precipitation radar (TRMM-PR) around the

\section{Discrepancy of PW and impact on downscaling}

H. G. Takahashi et al.

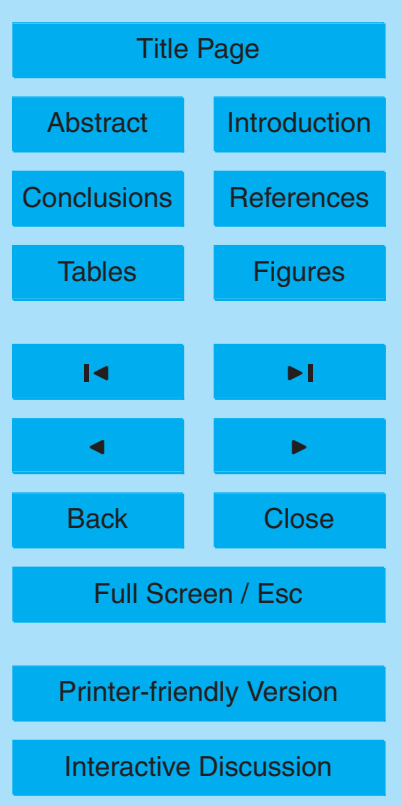


Indochina peninsula, J. Geophys. Res., 115, D07109, doi:10.1029/2009JD012155, 2010a. 23768, 23769

Takahashi, H. G., Yoshikane, T., Hara, M., Takata, K., and Yasunari, T.: High-resolution modelling of the potential impact of land surface conditions on regional climate over Indochina associated with the diurnal precipitation cycle, Int. J. Climatol., 30, 2004-2020, 2010b. 23764, 23769

Trenberth, K., Fasullo, J., and Smith, L.: Trends and variability in column-integrated atmospheric water vapor, Clim. Dynam., 24, 741-758, 2005. 23761

Trenberth, K., Fasullo, J., and Mackaro, J.: Atmospheric moisture transports from ocean to land and global energy flows in reanalyses, J. Climate, 24, 4907-4924, 2011. 23761

Uppala, S. M., KÅllberg, P. W., Simmons, A. J., Andrae, U., Bechtold, V. D. C., Fiorino, M., Gibson, J. K., Haseler, J., Hernandez, A., Kelly, G. A., Li, X., Onogi, K., Saarinen, S., Sokka, N., Allan, R. P., Andersson, E., Arpe, K., Balmaseda, M. A., Beljaars, A. C. M., Berg, L. V. D., Bidlot, J., Bormann, N., Caires, S., Chevallier, F., Dethof, A., Dragosavac, M., Fisher, M., Fuentes, M., Hagemann, S., Hólm, E., Hoskins, B. J., Isaksen, L., Janssen, P. A. E. M., Jenne, R., McNally, A. P., Mahfouf, J.-F., Morcrette, J.-J., Rayner, N. A., Saunders, R. W., Simon, P., Sterl, A., Trenberth, K. E., Untch, A., Vasiljevic, D., Viterbo, P., and Woollen, J.: The ERA-40 re-analysis, Q. J. Roy. Meteor. Soc., 131, 2961-3012, 2005. 23763

Wang, J. and Zhang, L.: Systematic errors in global radiosonde precipitable water data from comparisons with ground-based GPS measurements, J. Climate, 21, 2218-2238, 2008. 23763

Wild, M. and Liepert, B.: The Earth radiation balance as driver of the global hydrological cycle, Environ. Res. Lett., 5, 025203, doi:10.1088/1748-9326/5/2/025203, 2010. 23772

\section{ACPD}

12, 23759-23791, 2012

\section{Discrepancy of PW and impact on downscaling}

H. G. Takahashi et al.

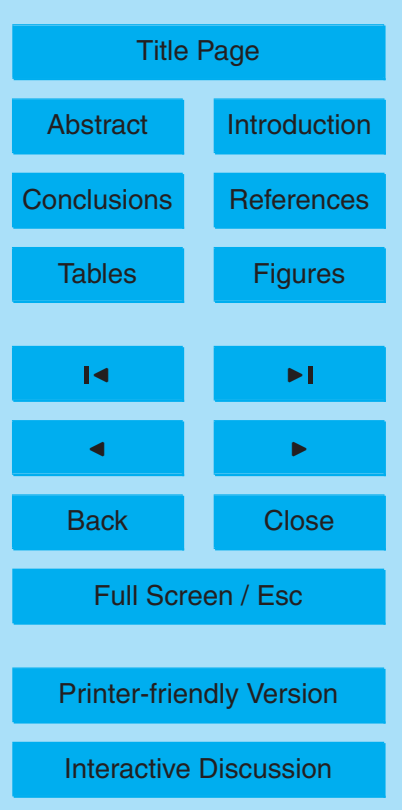




\section{ACPD}

12, 23759-23791, 2012

\section{Discrepancy of PW and impact on downscaling}

Table 1. Spatial pattern correlation coefficients among monthly mean $850-\mathrm{hPa}$ zonal (meridional) wind of ERAint, ERA40, NCEP2, and NCEP1 over the Southeast Asian domain (80$120^{\circ} \mathrm{E}, \mathrm{EQ}-30^{\circ} \mathrm{N}$ ) in July 1998 . The values in parentheses are the spatial pattern correlation coefficients of meridional winds. The spatial resolution of ERAint was changed to $2.5^{\circ}$ resolution by a simple linear interpolation, to calculate the pattern correlations. There were 221 samples. All values are statistically significant at the $99 \%$ confidence limit. The monthly mean monsoon westerly (zonal wind velocity) over the Southeast Asian domain $\left(90-110^{\circ} \mathrm{E}, 5-20^{\circ} \mathrm{N}\right.$ ) is shown in the bottom line.

\begin{tabular}{lcccc}
\hline Cor $(u, u)((v, v))$ & ERAint & ERA40 & NCEP2 & NCEP1 \\
\hline ERAint & - & $0.98(0.98)$ & $0.92(0.92)$ & $0.92(0.89)$ \\
ERA40 & - & - & $0.93(0.89)$ & $0.93(0.87)$ \\
NCEP2 & - & - & - & $0.98(0.96)$ \\
NCEP1 & - & - & - & - \\
\hline Monsoon & 4.76 & 4.68 & 4.73 & 4.68 \\
\hline
\end{tabular}

H. G. Takahashi et al.

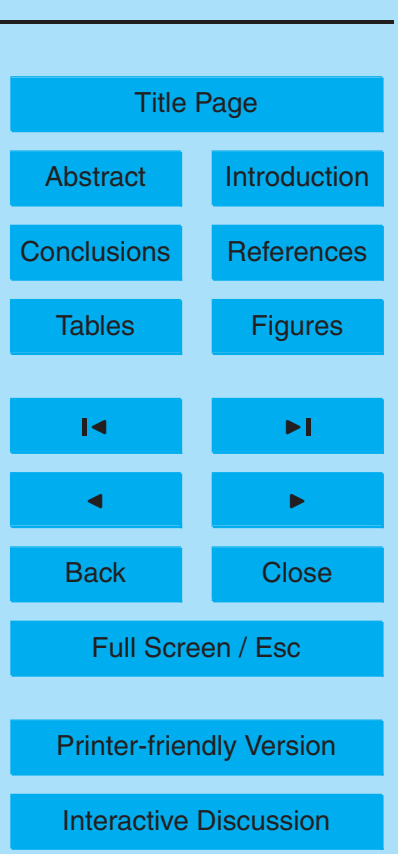




\section{ACPD}

12, 23759-23791, 2012

\section{Discrepancy of PW and impact on downscaling}

Table 2. Correlation coefficient among the daily mean $850-\mathrm{hPa}$ zonal (meridional) wind of ERAint, ERA40, NCEP2, and NCEP1 averaged over the Southeast Asia domain $\left(95-110^{\circ} \mathrm{E}\right.$, $5-20^{\circ} \mathrm{N}$ ) in July 1998 . The values in parentheses are the correlation coefficients of meridional winds. There were 31 samples. All values are statistically significant at the $99 \%$ confidence limit.

\begin{tabular}{lcccc}
\hline Cor $(u, u)((v, v))$ & ERAint & ERA40 & NCEP2 & NCEP1 \\
\hline ERAint & - & $0.99(0.97)$ & $0.98(0.97)$ & $0.98(0.96)$ \\
ERA40 & - & - & $0.98(0.95)$ & $0.98(0.95)$ \\
NCEP2 & - & - & - & $0.99(0.96)$ \\
NCEP1 & - & - & - & - \\
\hline
\end{tabular}

H. G. Takahashi et al.
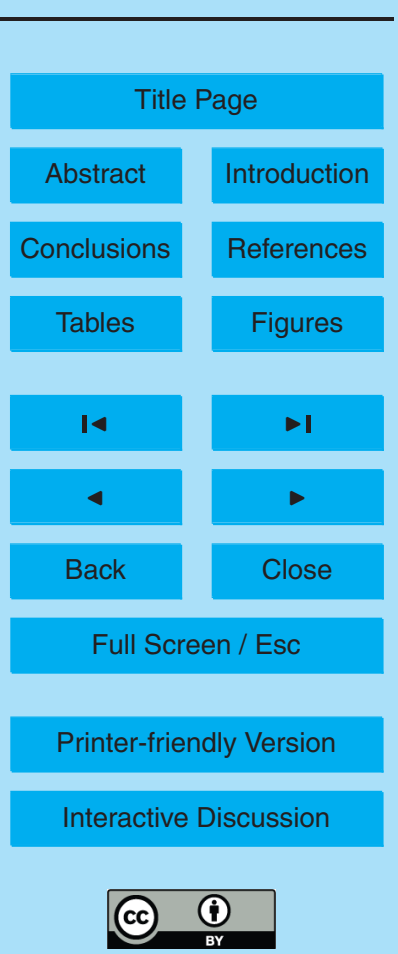


\section{ACPD}

12, 23759-23791, 2012

\section{Discrepancy of PW and impact on downscaling}

H. G. Takahashi et al.

Table 3. Monthly mean 850-hPa wind divergence of ERAint, ERA40, NCEP2, and NCEP1 over the Southeast Asia domain $\left(95-110^{\circ} \mathrm{E}, 5-20^{\circ} \mathrm{N}\right.$ ) in July 1998 . A positive (negative) value shows the wind divergence (convergence). The units are $\mathrm{s}^{-1}$.

\begin{tabular}{lr}
\hline & divergence in $850 \mathrm{hPa}\left(\mathrm{s}^{-1}\right)$ \\
\hline ERAint & $3.17 \times 10^{-7}$ \\
ERA40 & $-6.27 \times 10^{-7}$ \\
NCEP2 & $-3.74 \times 10^{-7}$ \\
NCEP1 & $-3.08 \times 10^{-7}$ \\
\hline
\end{tabular}

Title Page

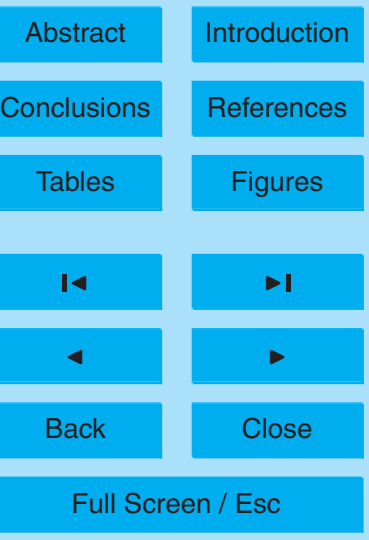

Printer-friendly Version

Interactive Discussion 


\section{ACPD}

12, 23759-23791, 2012

\section{Discrepancy of PW and impact on downscaling}

Table 4. Spatial pattern correlation coefficients among monthly mean simulated 850-hPa zonal (meridional) wind of DS-ERAint, DS-ERA40, DS-NCEP2, and DS-NCEP1 over the D2 domain $\left(97-107.5^{\circ} \mathrm{E}, 10-18^{\circ} \mathrm{N}\right)$ in July 1998 . The values in parentheses are the spatial pattern correlation coefficients of simulated meridional winds. There were 340012 samples (we calculated the correlation on a $0.0158^{\circ}$ latitude $\times 0.0158^{\circ}$ longitude grid). All values are statistically significant at the $99 \%$ confidence limit.

\begin{tabular}{lcccc}
\hline Cor $(u, u)((v, v))$ & DS-ERAint & DS-ERA40 & DS-NCEP2 & DS-NCEP1 \\
\hline DS-ERAint & - & $0.97(0.93)$ & $0.86(0.90)$ & $0.89(0.92)$ \\
DS-ERA40 & - & - & $0.86(0.94)$ & $0.85(0.85)$ \\
DS-NCEP2 & - & - & - & $0.96(0.89)$ \\
DS-NCEP1 & - & - & - & - \\
\hline
\end{tabular}

H. G. Takahashi et al.

Title Page

Abstract

Conclusions

Tables

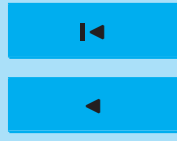

Back

\section{Full Screen / Esc}

Printer-friendly Version

Interactive Discussion 


\section{ACPD}

12, 23759-23791, 2012

\section{Discrepancy of PW and impact on downscaling}

Table 5. Correlation coefficient among downscaled daily mean $850-\mathrm{hPa}$ zonal (meridional) wind of DS-ERAint, DS-ERA40, DS-NCEP2, and DS-NCEP1 averaged over the D2 domain (97$107.5^{\circ} \mathrm{E}, 10-18^{\circ} \mathrm{N}$ ) in July 1998 . The values in parentheses are the correlation coefficients of meridional winds. There were 31 samples. All values are statistically significant at the $99 \%$ confidence limit.

\begin{tabular}{lcccc}
\hline Cor $(u, u)((v, v))$ & DS-ERAint & DS-ERA40 & DS-NCEP2 & DS-NCEP1 \\
\hline DS-ERAint & - & $0.95(0.96)$ & $0.91(0.82)$ & $0.90(0.84)$ \\
DS-ERA40 & - & - & $0.83(0.82)$ & $0.85(0.79)$ \\
DS-NCEP2 & - & - & - & $0.85(0.73)$ \\
DS-NCEP1 & - & - & - & - \\
\hline
\end{tabular}

H. G. Takahashi et al.

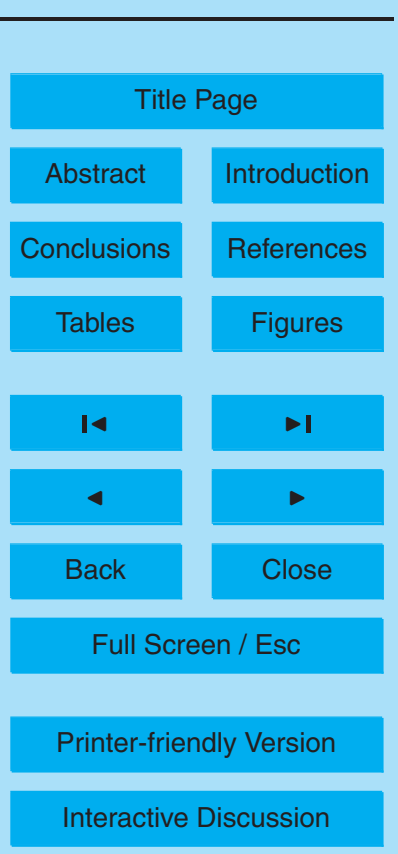




\section{ACPD}

12, 23759-23791, 2012

\section{Terrain Height in D1}

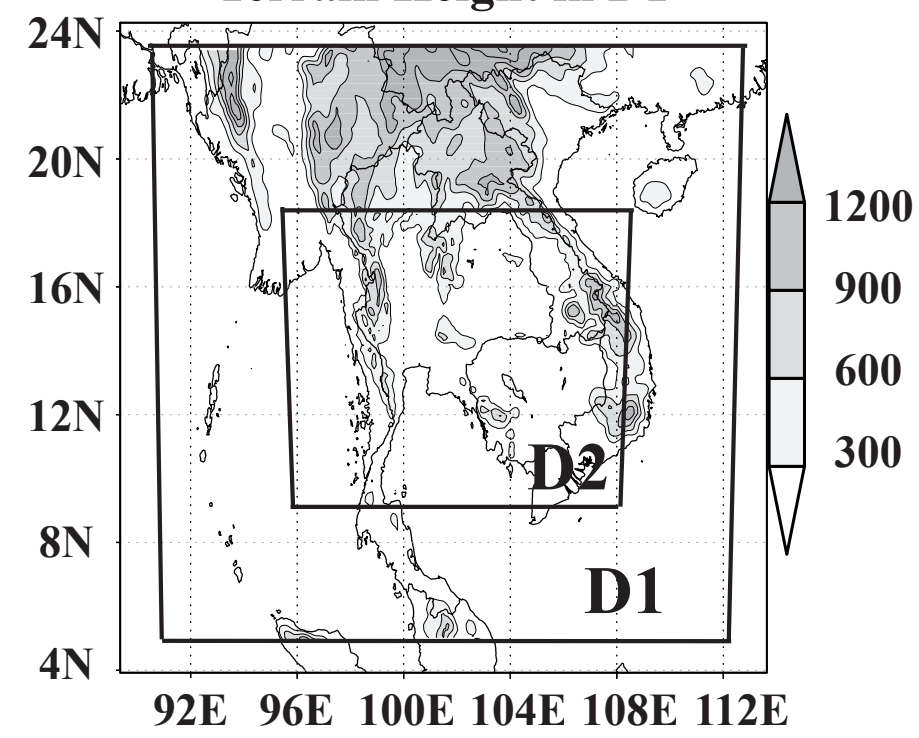

Fig. 1. Domains of a numerical experiment using a regional climate model. The terrain height is denoted by the gray scale.

\section{Discrepancy of PW and impact on downscaling}

H. G. Takahashi et al.

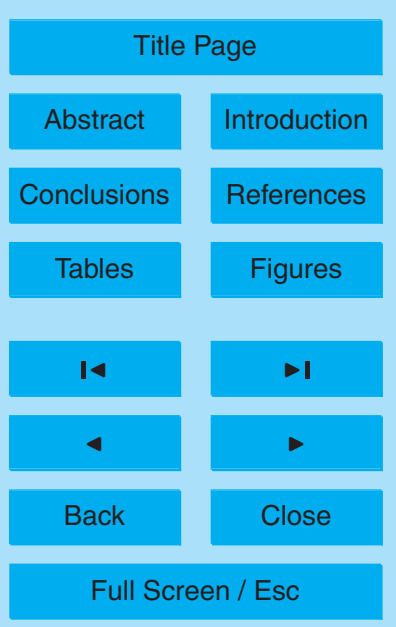

Printer-friendly Version

Interactive Discussion 


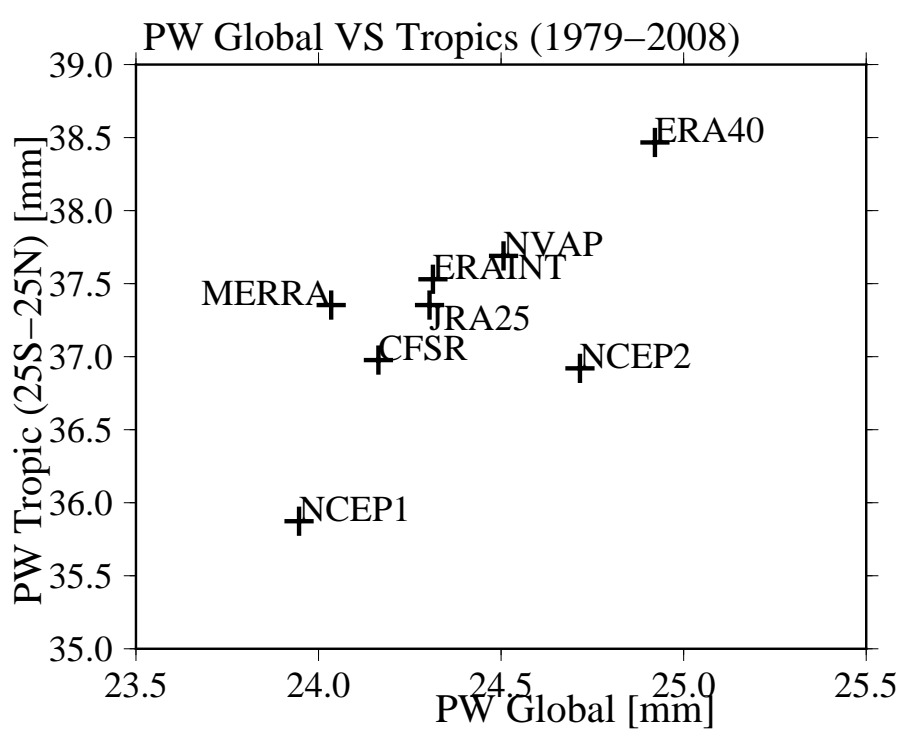

Fig. 2. Scatter plot between annual and global mean PW and the annual and tropical mean PW in the reanalyses and observation. The PWs were averaged over $30 \mathrm{yr}$ from 1979 to 2008 except for ERA40 and NVAP. PW of ERA40 was averaged over $23 \mathrm{yr}$ from 1979 to 2001. PW of NVAP was averaged over $12 \mathrm{yr}$ from 1988 to 1999. The units of the $\mathrm{x}$-axis and $\mathrm{y}$-axis are $\mathrm{mm}$.
12, 23759-23791, 2012

\section{Discrepancy of PW and impact on downscaling}

H. G. Takahashi et al.

Title Page

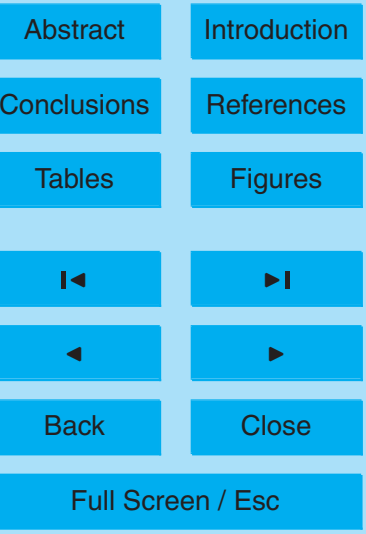

Printer-friendly Version

Interactive Discussion 


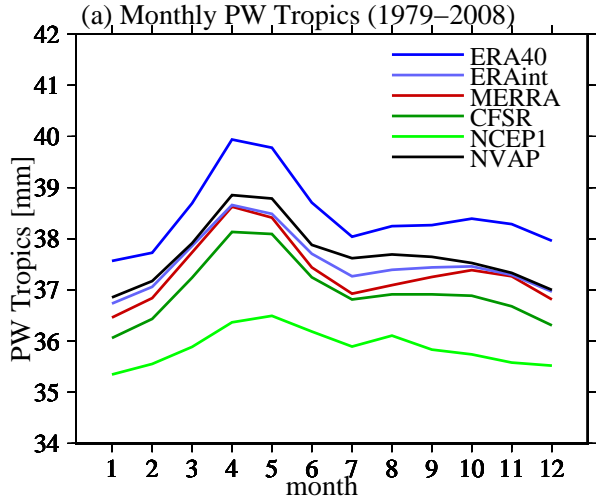

\section{ACPD}

12, 23759-23791, 2012

\section{Discrepancy of PW and impact on downscaling}

H. G. Takahashi et al.

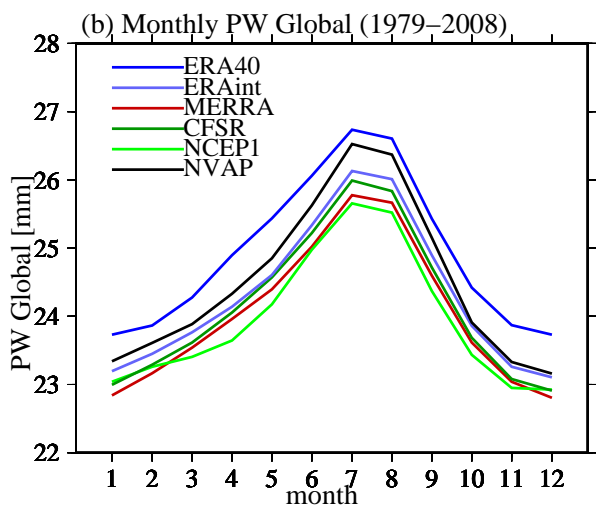

Title Page

Abstract

Introduction

Conclusions

References

Tables

Figures

14

4

\section{Back}

Close

Full Screen / Esc

PW of five major reanalyses and observation over $30 \mathrm{yr}$ from 1979 to 2008 except for ERA40 and NVAP. PW of ERA40 was averaged over $23 \mathrm{yr}$ from 1979 to 2001. PW of NVAP was averaged over $12 \mathrm{yr}$ from 1988 to 1999 . The black line shows the seasonal march of PW of NVAP. The blue, light-blue, red, green, and light-green lines show the seasonal marches of PW of ERA40, ERAint, MERRA, CFSR, and NCEP1, respectively. We omitted JRA25 and NCEP2. The units are $\mathrm{mm}$.

Printer-friendly Version

Interactive Discussion 


\section{ACPD}

12, 23759-23791, 2012

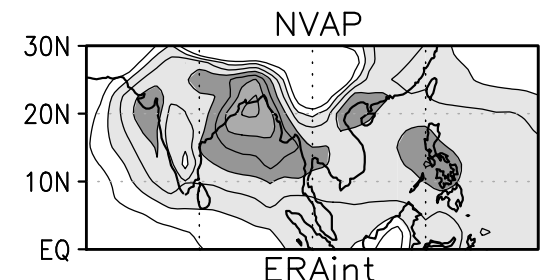

ERA40
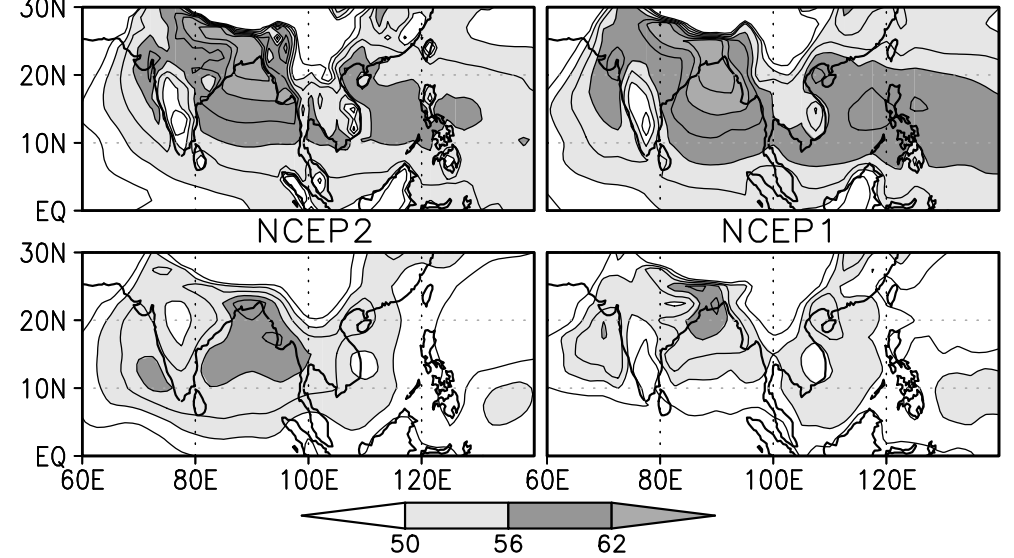

Fig. 4. Climatological monthly mean PWs of NVAP, ERAint, ERA40, NCEP2, and NCEP1 in July over $12 \mathrm{yr}$ from 1988 to 1999 over the Southeast Asian monsoon region. Contours are plotted from $47 \mathrm{~mm}$ to $65 \mathrm{~mm}$ with a $3 \mathrm{~mm}$ interval. The units are $\mathrm{mm}$.

\section{Discrepancy of PW and impact on downscaling}

H. G. Takahashi et al.

\section{Title Page}

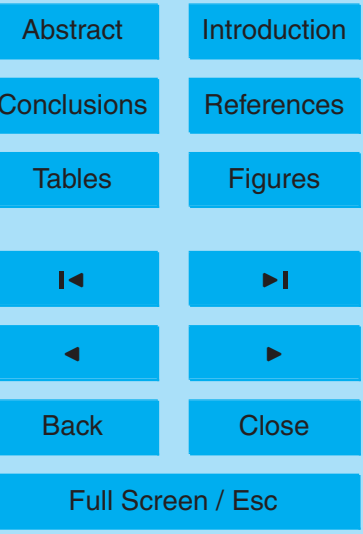

Printer-friendly Version

Interactive Discussion 


\section{ACPD}

12, 23759-23791, 2012

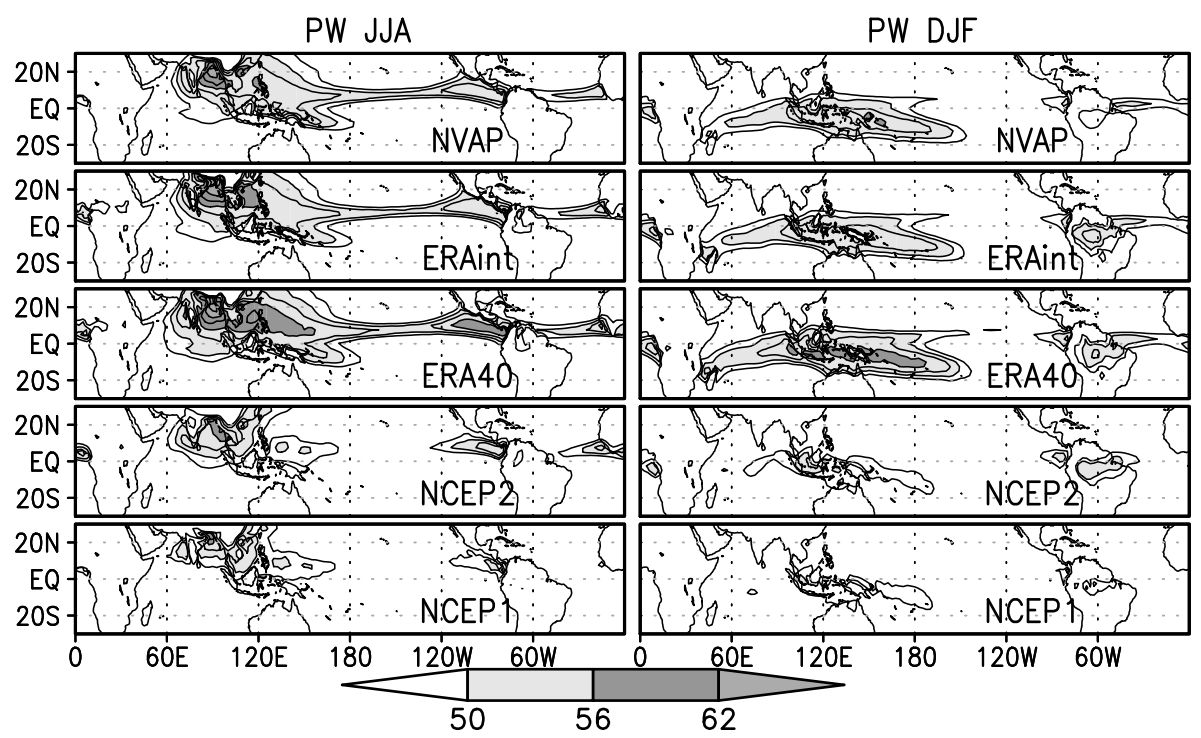

Fig. 5. Monthly mean PWs of NVAP, ERAint, ERA40, NCEP2, and NCEP1 over $12 \mathrm{yr}$ from 1988 to 1999 in June-July-August (left panels) and December-January-February (right panels). Contours are plotted from $47 \mathrm{~mm}$ to $65 \mathrm{~mm}$ with a $3 \mathrm{~mm}$ interval. The units are $\mathrm{mm}$.

\section{Discrepancy of PW and impact on downscaling}

H. G. Takahashi et al.

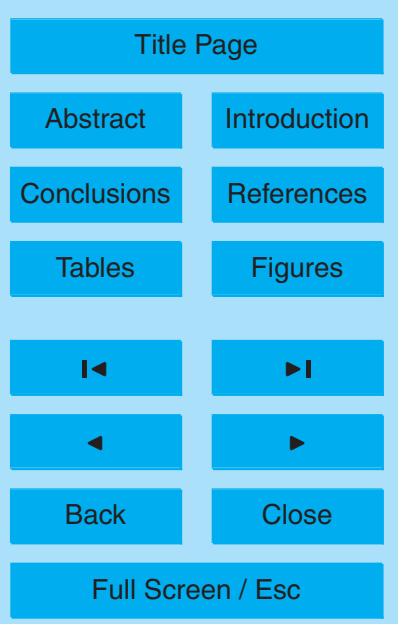

Printer-friendly Version

Interactive Discussion

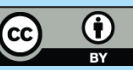




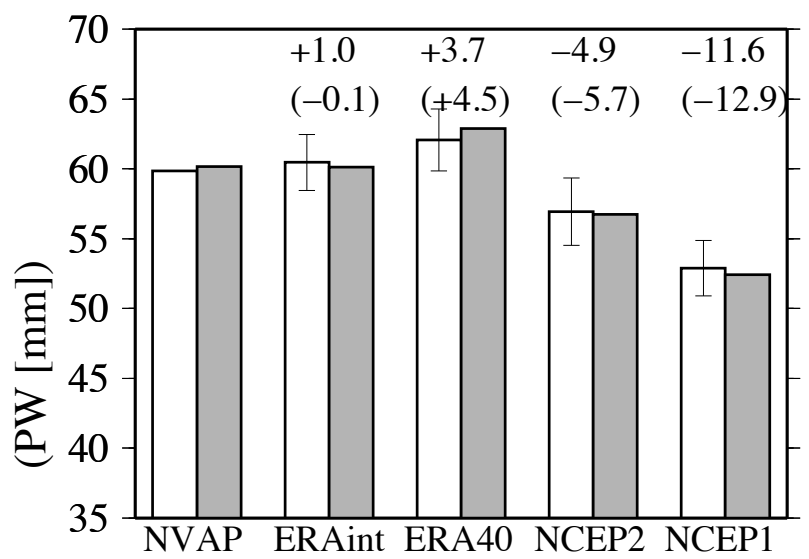

Fig. 6. Left open (light-gray) bars indicate the 12-yr mean of PW in July (monthly mean PW

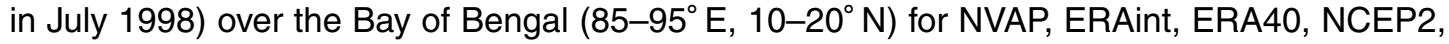
and NCEP1. Error bars indicate the interannual standard deviations for $30 \mathrm{yr}$ from 1979 to 2008 (23 yr from 1979 to 2001 for ERA40). The values of the climatological PW (PW in July 1998) are shown in proportion to the observations.

\section{ACPD}

12, 23759-23791, 2012

\section{Discrepancy of PW and impact on downscaling}

H. G. Takahashi et al.

\section{Title Page}

\section{Abstract} Introduction

Conclusions References

Tables

Figures

14

4

Back

Close

Full Screen / Esc

Printer-friendly Version

Interactive Discussion 


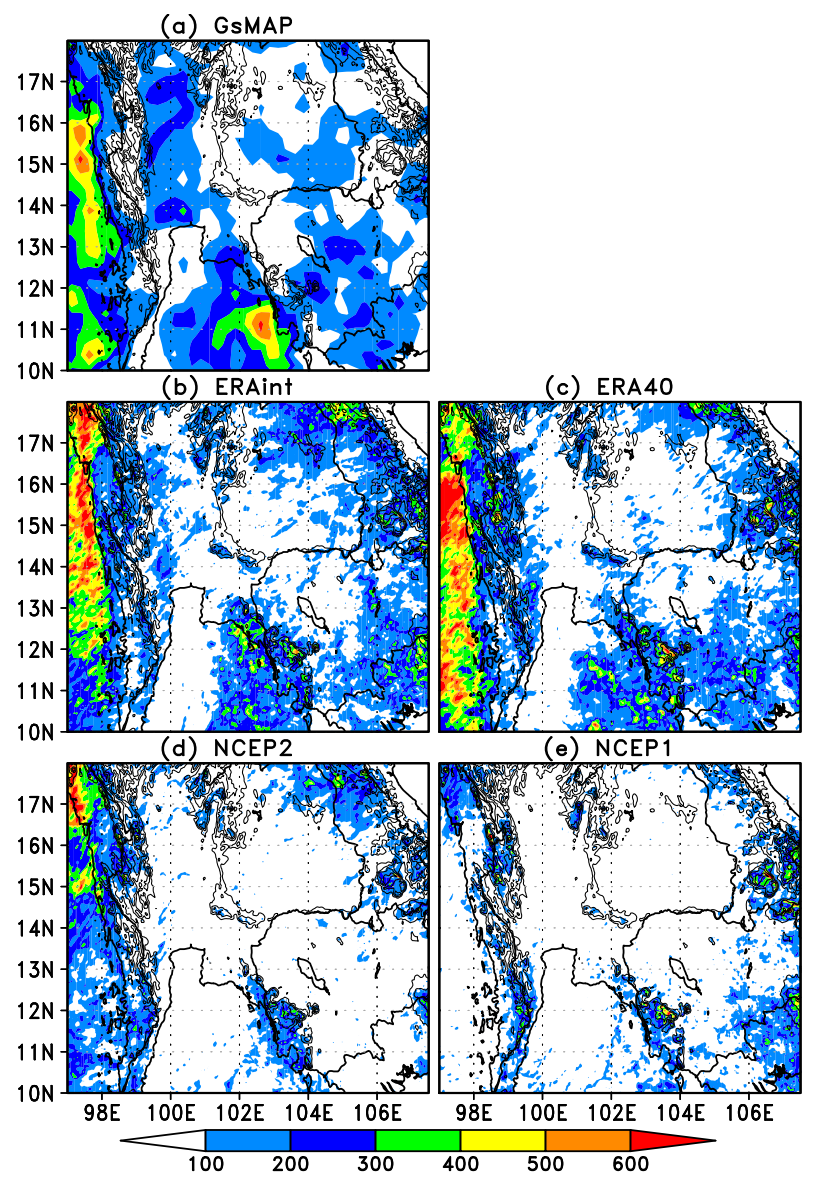

Fig. 7. Observed and simulated rainfall over and around the Indochina Peninsula. (a) Observed (GSMaP), (b) DS-ERAint, (c) DS-ERA40, (d) DS-NCEP2, and (e) DS-NCEP1 are shown. The units are mm month ${ }^{-1}$. The thin black contours show the terrain height in the inner domain $(300$, $600,900,1200,1500$, and $1800 \mathrm{~m})$.

\section{ACPD}

12, 23759-23791, 2012

\section{Discrepancy of PW and impact on downscaling}

H. G. Takahashi et al.

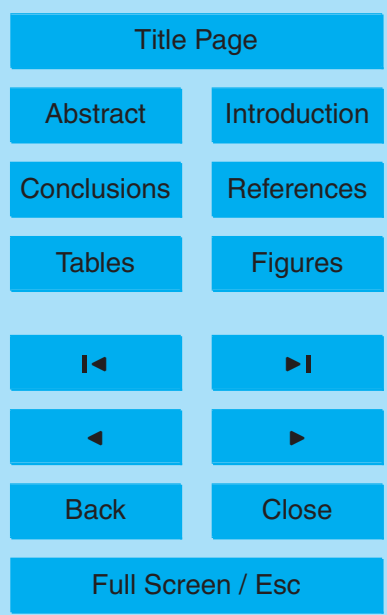

Printer-friendly Version

Interactive Discussion 


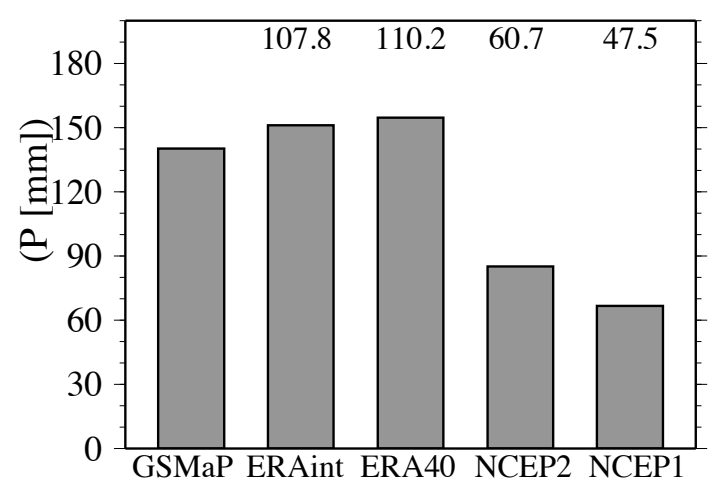

Fig. 8. Observed and simulated rainfall amounts averaged over the Indochina domain (97$107.5^{\circ} \mathrm{E}, 10-18^{\circ} \mathrm{N}$ ). The values for the rainfall are shown as a proportion of the observed amounts.

\section{ACPD}

12, 23759-23791, 2012

\section{Discrepancy of PW and impact on downscaling}

H. G. Takahashi et al.

Title Page

Abstract Introduction

Conclusions References

Tables

Figures

14

4

Back

Close

\section{Full Screen / Esc}

Printer-friendly Version

Interactive Discussion 


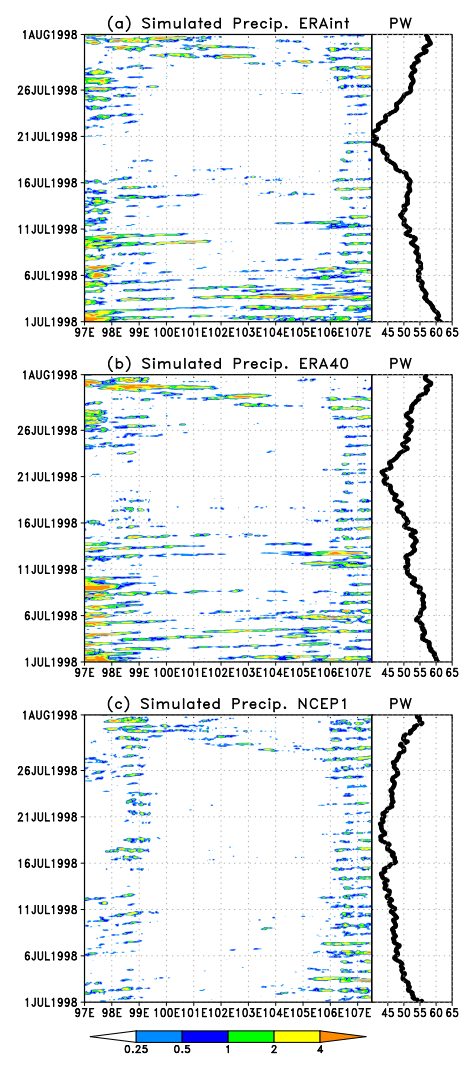

\section{ACPD}

12, 23759-23791, 2012

\section{Discrepancy of PW and impact on downscaling}

H. G. Takahashi et al.

Title Page

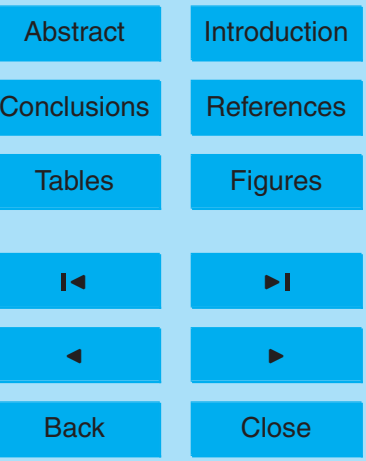

Full Screen / Esc

Fig. 9. The left-hand panels show longitude-time cross section of the simulated precipitation of (a) DS-ERAint, (b) DS-ERA40, and (c) DS-NCEP1 along the $15^{\circ} \mathrm{N}$ latitudinal band, which was averaged between $14^{\circ} \mathrm{N}$ and $16^{\circ} \mathrm{N}$. The units are $\mathrm{mm} \mathrm{h}^{-1}$. The right-hand panels show the averaged PWs of the Indochina domain $\left(97-107.5^{\circ} \mathrm{E}, 10-18^{\circ} \mathrm{N}\right)$ : (a) DS-ERAint, (b) DSERA40, and (c) DS-NCEP1. The units are $\mathrm{mm}$.

Printer-friendly Version

Interactive Discussion 